\title{
KAJIAN PERILAKU PENGENDARA DAN KECEPATAN KENDARAAN PADA JALAN EMPAT LAJUR DUA ARAH TERBAGI DI KOTA PONTIANAK
}

\author{
A Study for Behaviour of Rider and Velocity of Vehicles on \\ Divided Four Lane Two Way in Pontianak
}

\author{
Slamet Widodo \\ Jurusan Teknik Sipil \\ Fakultas Teknik \\ Universitas Tanjungpura \\ Jln. Prof. Dr. Hadar Nawawi, \\ Pontianak, Kalimantan Barat \\ slametwidodo@civil.untan.ac.id
}

\author{
Elsa Tri Mukti \\ Jurusan Teknik Sipil \\ Fakultas Teknik \\ Universitas Tanjungpura \\ Jln. Prof. Dr. Hadar Nawawi, \\ Pontianak, Kalimantan Barat \\ elsatrimukti@civil.untan.ac.id
}

\author{
Sonya Sulistyono \\ Jurusan Teknik Sipil \\ Fakultas Teknik \\ Universitas Jember \\ Jln. Kalimantan No.37, \\ Jember, Jawa Timur \\ sonya.sulistyono@unej.ac.id
}

\begin{abstract}
Jalan Ahmad Yani in Pontianak as National road was located in the Capital of Kalimantan Barat Province has a four-lane two carriageway facility and a median in the middle of lanes. It has a high volume of traffic, i.e., more than 100 thousand a day for two directions. A number of the vehicle was recorded by installing CCTV device, a while velocity of vehicles are used a couple of speed gun. It was dominated by the number of the motorcycle around $70 \%$, light vehicle, and the heavy vehicle is $29.6 \%$ and $0.4 \%$, respectively. Based on data collected in the front of Prosecutor's building that average of vehicle velocity is around 36.0 to $43.0 \mathrm{~km} / \mathrm{h}$ and speed of a light vehicle is higher than other of vehicle types, while at other location (in the front of Ayani Mega Mall) it has not a certain trend. The rider of the motorcycle is riding their vehicle around $44 \%$, going out of a provided lane for motorists. Perception's respondents reveal that it is still probable that an incident has happened although they can ride. Speeding behavior of rider related to reaching a destination earlier. For speed restricted, respondents said that it was useful for reducing the number of incident and fatality. A sanction, like a revocation for riding license for awhile, is preferred but not permanent revocation. Some answers from respondents state that they obey some regulations during riding.
\end{abstract}

Keywords: traffic volume, perception, speeding, responden, incident

\begin{abstract}
Abstrak
Lokasi penelitian adalah Jalan Ahmad Yani di kota Pontianak yang merupakan ibukota Provinsi Kalimantan Barat dimana jalan tersebut minimal memiliki 4 lajur 2 arah terbagi, berstatus Jalan Nasional. Volume lalulintas sangat tinggi melebihi 100 ribu kendaraan untuk 2 arah pada hari kerja (workday) dengan modal split sekitar 50:50. Pengambilan data lalu-lintas dilakukan dengan memasang CCTV untuk 2 arah, sedangkan kecepatan kendaraan digunakan speed gun. Jumlah kendaraan jenis Sepeda Motor (MC) mendominasi sekitar $70 \%$, sementara jenis Kendaraan Ringan (LV) sebesar 29,6\% dan jenis Kendaraan Berat sebesar 0,4\%. Di lokasi depan gedung Kejaksaan Kalimantan Barat bahwa kecepatan rata-rata kendaraan berkisar 36,0 s.d. 43,0 km/jam. Rata-rata kecepatan kendaraan jenis LV relatif tinggi dibandingkan jenis kendaraan lain, sedangkan di lokasi depan Ayani Mega Mal tidak didapatkan polanya. Terhadap kepatuhan pada lajur bahwa kendaraan jenis Sepeda Motor (LV) sekitar 44\% keluar dari lajur khusus sepeda motor yang telah disediakan, bahkan penelitian sebelumnya di tahun 2014 bahwa jumlah kendaraan jenis MC yang keluar lajur berkisar 55\%. Dari persepsi pengendara bahwa kecelakaan mungkin saja terjadi walau sudah terampil berkendara. Perilaku ngebut di jalan beralasan agar sampai tujuan lebih cepat. Terhadap pembatasan kecepatan, responden meyakini dapat mengurangi kecelakaan dan fatalitas. Sanksi berupa pencabutan SIM untuk sementara waktu disetujui namun tidak untuk pencabutan SIM selamanya. Responden menyatakan patuh saat berkendara di jalan raya terhadap peraturan yang ada.
\end{abstract}

Kata kunci: volume lalu-lintas, persepsi, ngebut, responden, kecelakaan 


\section{PENDAHULUAN}

Perilaku berkendara di jalan raya mencerminkan sikap seseorang khususnya berkaitan dengan pengendara lain. Pengendara yang ceroboh atau ugal-ugalan mempunyai kontribusi terhadap kecelakaan yang terjadi. Setiap tahun di dunia sekitar 1,3 juta orang meninggal di jalan dan selain itu lebih dari 25 juta orang menderita cacat permanen sebagai akibat kecelakaan lalu-lintas. Namun demikian, dibeberapa negara maju telah terjadi penurunan tingkat kecelakaan akibat dilaksanakannya Program Keselamatan Jalan secara aktif selama 50 tahun terakhir. Kecelakaan lalu-litas diprediksi menjadi penyebab kematian ke-5 terbesar di dunia pada tahun 2030 dan kerugian yang ditanggung masyarakat diperkirakan $2 \%$ dari total penghasilan domestik regional bruto (PDRB), untuk Indonesia berdasarkan hasil penelitian bahwa kerugian diperkirakan 2,9\% dari PDRB. Berdasarkan beberapa penelitian tentang berkendara di jalan raya bahwa perilaku pengemudi di jalan raya sangat mempengaruhi jumlah kecelakaan yang terjadi. Kelompok besar terjadinya kecelakaan sebagai akibat faktor manusia yaitu tidak tertib berkendara di jalan raya seperti kecepatan yang kencang atau (speeding) ngebut (Finch, et,al, 1994), tidak mentaati garis/marka jalan saat menyiap kendaraan (overtaking) (Dishub Kalbar ,2017). Faktor manusia yang berkontribusi pada peristiwa kecelakaan nilainya lebih dari $60 \%$, kemudian diikuti faktor kendaraan dan faktor terakhir adalah lingkungan jalan. Melalui jalan yang berkesalamatan dan dipergunakan dalam distribusi barang maupun orang yang diharapkan berjalan lancar, sehingga dengan demikian maka jalan tersebut akan memberikan kontribusi yang cukup besar bagi aktifitas masyarakat. Sektor transportasi merupakan sektor penunjang bagi kegiatan sektor lainnya, dimana sektor ini memegang peranan yang cukup penting dari segi sosial maupun ekonomi untuk provinsi Kalimantan Barat. Hal ini diharapkan dapat meningkatkan pertumbuhan ekonomi masyarakat, khususnya untuk kelancaran distribusi barang maupun orang yang didukung oleh kehandalan sarana maupun prasarana transportasi yang ada.

Perilaku pengendara di jalan raya, kondisi lingkungan jalan seperti penerangan, rambu lalu-lintas, dan kondisi permukaan jalan serta kondisi kendaraan bermotor yang dikendarai memberikan sumbangan terhadap terjadinya kecelakaan di jalan raya. Studi-studi terdahulu menunjukkan bahwa proporsi terbesar penyebab kecelakaan adalah faktor pengendara. Namun lingkungan jalan juga berperan terhadap kecelakaan yang terjadi. Oleh karena perilaku pengendara di jalan memberikan sumbangan terbesar pada terjadinya kecelakaan, maka edukasi berupa peningkatan pengetahuan, kesadaran berkendara dan mentaati/patuh pada peraturan perlu dipahami oleh pengendara

\section{PENGUMPULAN DATA}

\section{Metode Pengumpulan Data}

Pada penelitian ini, pengumpulan data primer dilakukan dengan 3 (tiga) cara yakni pertama, perekaman volume kendaraan dilakukan dengan memasang peralatan CCTV (Closed Circuit Television). Kedua, pencacahan kecepatan kendaraan dilakukan dengan menggunakan speedgun. Ketiga, persepsi pengemudi didapatkan melalui survei secara online. Selain itu, pengumpulan data secara manual juga dilakukan seperti memfoto marka jalan, mengukur superelevasi, merekam menggunakan kamera video untuk rambu. Juga aplikasi googlemaps khususnya street view dimanfaatkan. 


\section{Survei Lapangan}

Sesuai kesepakatan sebelumnya bahwa kriteria lokasi jalan yang digunakan sebagai lokasi studi adalah berstatus Jalan Nasional berada di Ibukota Provinsi yang mempunyai setidaknya 2 lajur setiap arahnya, memiliki median di tengahnya, selain pergerakan lalulintas dua arah bahwa panjang jalan sekitar $5 \mathrm{~km}$ dengan alignmen relatif lurus. Berdasarkan kriteria tersebut, ditetapkan Jalan Ahmad Yani sebagai lokasi studi pada penelitian ini, seperti resume pada Tabel 1. berikut:

Tabel 1. Ruas Jalan Nasional di Kota Pontianak

\begin{tabular}{cclcc}
\hline No. & Kode Ruas & \multicolumn{1}{c}{ Nama Ruas } & Panjang (Km) & Tipe \\
\hline 1 & $010-11-\mathrm{K}$ & Jln. Khatulistiwa & 6,88 & $2 / 2$ UD \\
2 & $010-12-\mathrm{K}$ & Jln. Gusti Situt Mahmud & 2,31 & $2 / 2 / \mathrm{UD}$ \\
3 & $010-13-\mathrm{K}$ & Jln.Sultan Hamid II (Jln. Perintis Kemerdekaan) & 3,43 & $2 / 2 / \mathrm{UD}$ \\
4 & $011-11-\mathrm{K}$ & Jln. Kom. Yos. Sudarso & 5,68 & $2 / 2$ UD \\
5 & $011-12-\mathrm{K}$ & Jln. Pak Kasih & 0,69 & $4 / 2 \mathrm{D}$ \\
6 & $011-13-\mathrm{K}$ & Jln. Rahadi Usman & 0,37 & $4 / 2$ UD \\
7 & $011-14-\mathrm{K}$ & Jln. Tanjungpura & 2,11 & $4 / 2 \mathrm{D}$ \\
8 & $011-15-\mathrm{K}$ & Jln. Pahlawan & 0,35 & $4 / 2 \mathrm{D}$ \\
9 & $011-16-\mathrm{K}$ & Jln. Veteran & 0,69 & $4 / 2 \mathrm{D}$ \\
$\mathbf{1 0}$ & $\mathbf{0 1 1 - 1 7 - K}$ & Jln. Ahmad Yani & $\mathbf{3 , 3 6}$ & $\mathbf{4 / 2} \mathbf{D}$ \\
11 & $012-11-\mathrm{K}$ & Jln. Ya' M. Sabran & 2,470 & $2 / 2$ UD \\
\hline
\end{tabular}

Sumber: https://www.geoportal.kalbarprov.go.id \& survei pengamatan/pengukuran

Pengumpulan data jalan seperti superelavasi, marka dipermukaan jalan dilakukan secara manual. Superelevasi Jalan Ahmad Yani berkisar 1\%, lebar marka garis sekitar $12 \mathrm{~cm}$, lebar lajur 2,7 s.d. $3,0 \mathrm{~m}$.

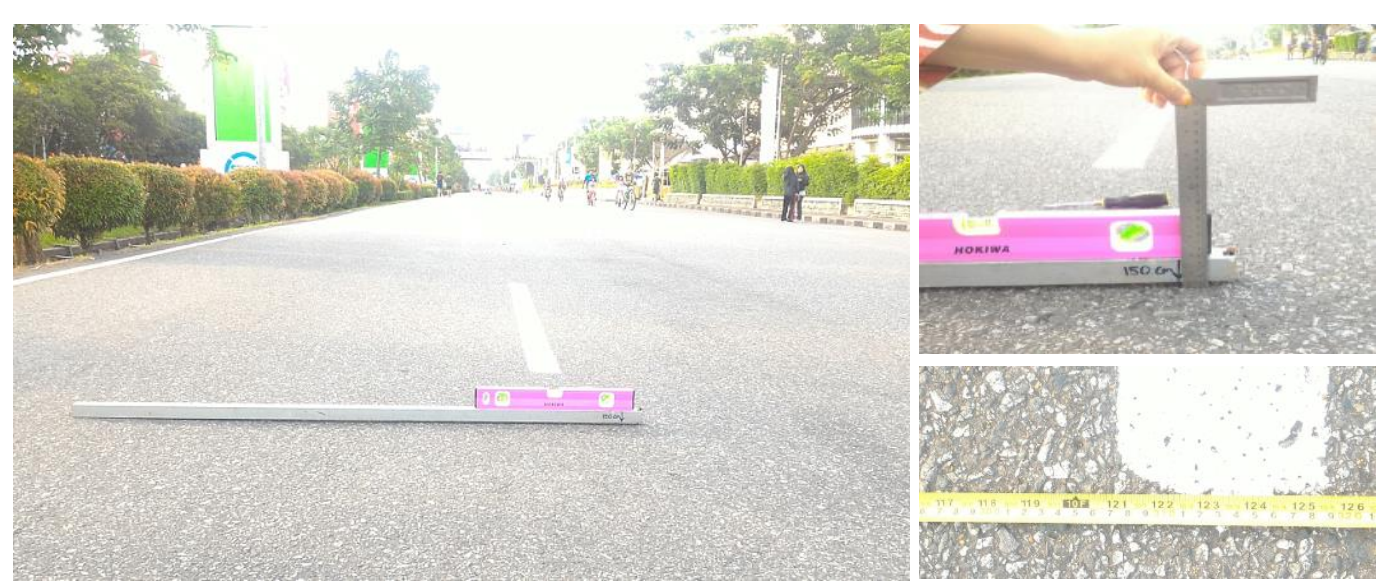

Gambar 1. Pengukuran superelevasi dan marka di Jalan Ahmad Yani

Rambu yang ada di jalan meliputi 4 jenis yaitu Rambu Petunjuk, Rambu Larangan, Rambu Perintah, dan Rambu Peringatan. Sepanjang jaan Ahmad Yani yang paling banyak adalah jenis Rambu Larangan yakni Dilarang Berhenti. 
Marka yang tersedia di Jalan Ahmad Yani meiputi: Marka untuk Lajur Sepeda, Lajur Sepeda Motor, Garis Menerus di tepi dan di tengah, Garis Putus-Putus di Tengah, Zebra Cross, Stopline, Yellow Box, Ruang Henti Kendaraan.

Gambaran sekilas untuk marka dan rambu di lokasi studi seperti tampak pada Gambar 2. berikut:
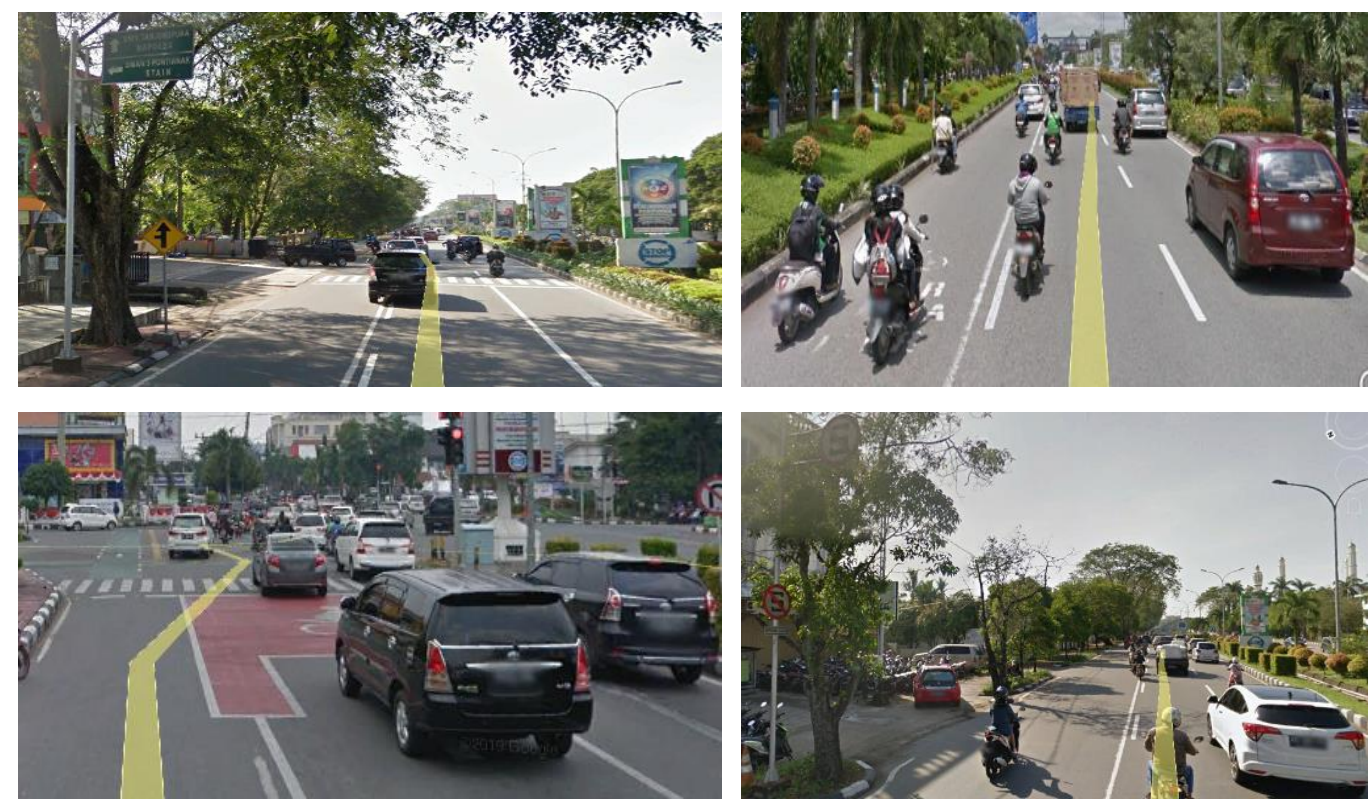

Gambar 2. View marka dan rambu di Jalan Ahmad Yani

\section{Kecepatan Kendaraan}

Pencatatan kecepatan kendaraan dilakukan untuk jenis kendaraan Sepeda Motor (MC), Kendaraan Ringan (LV), dan Kendaraan Berat (HV). Pengelompokkan kendaraan sesuai MKJI 1997.Setiap jenis kendaraan diambil 60 kendaraan, namun untuk jenis HV tidak tercapai 60 unit disebabkan jumlahnya sedikit saat pengambilan data jam sibuk siang atau malam. Periode pengambilan data kecepatan saat Siang dan Malam hari, saat lalu-lintas Sibuk (onpeak) dan Lengang (off-peak) sebagaimana dijelaskan pada tabel berikut:

Tabel 2. Rentang waktu survei kecepatan kendaraan

\begin{tabular}{clcc}
\hline No. & Kondisi Lalu-lintas & Jam & Waktu \\
\hline 1 & Sibuk (on-peak) & 6.30 s.d. 8.30 & Siang \\
\hline 2 & Lengang (off-peak) & 9.30 s.d. 11.00 & \\
\hline 3 & Sibuk (on-peak) & 18.30 s.d. 20.00 & Malam \\
\hline 4 & Lengang (off-peak) & 21.30 s.d. 22.00 & \\
\hline
\end{tabular}




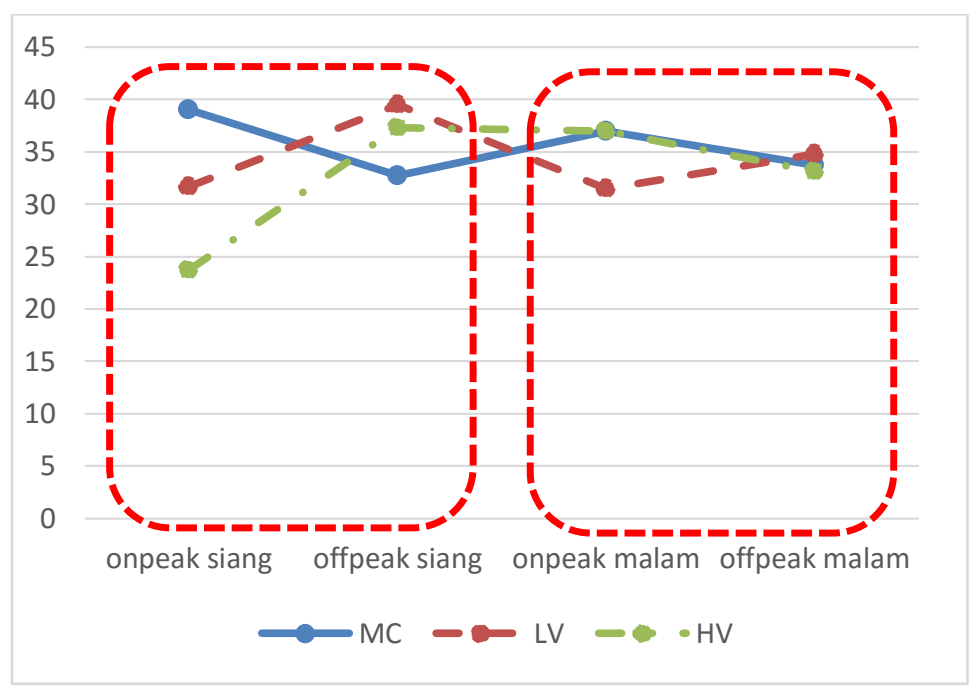

Gambar 3. Kecepatan rata-rata kendaraan di depan Ayani Mal

Kecepatan kendaraan pada saat lalu-lintas sibuk dan lengang untuk ruas jalan Ahmad Yani di depan Kantor Kejaksaan Kalimantan Barat adalah sebagai berikut:

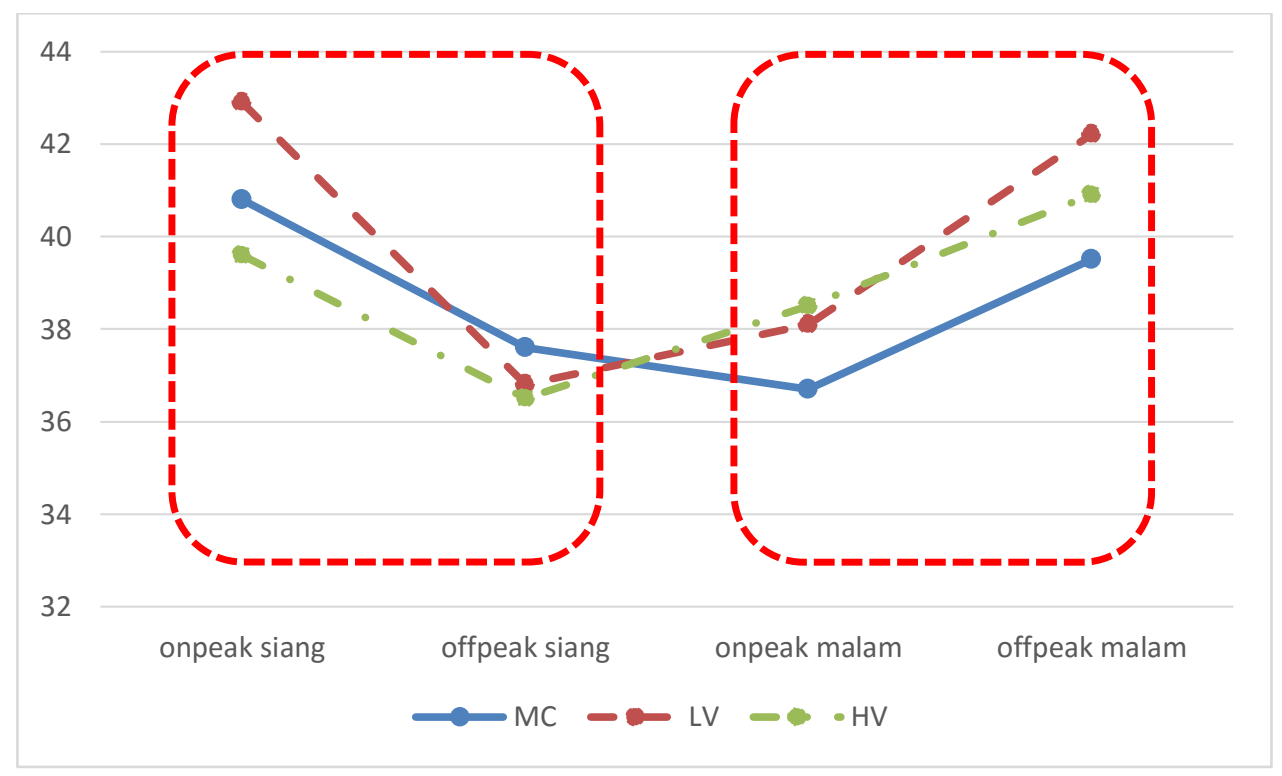

Gambar 4. Kecepatan rata-rata kendaraan di depan Kejaksaan Kalbar

\section{Volume Kendaraan}

Jalan Ahmad Yani merupakan jalan yang sangat penting dan relatif padat. Resume beberapa penelitian (Ismurdianto, 2013;Pratama, 2014; Zainuddin, 2014) menunjukkan bahwa volume kendaraan di jalan tersebut melebihi 100 ribu kendaraan untuk 2 arah dalam satu hari satu malam (24 jam). Fluktuasi lalu-lintas kendadaan di jalan Ahmad Yani pada hari kerja yang diambil hari Senin di bulan Mei 2019 sebagaimana ditunjukkan pada gambar berikut: 


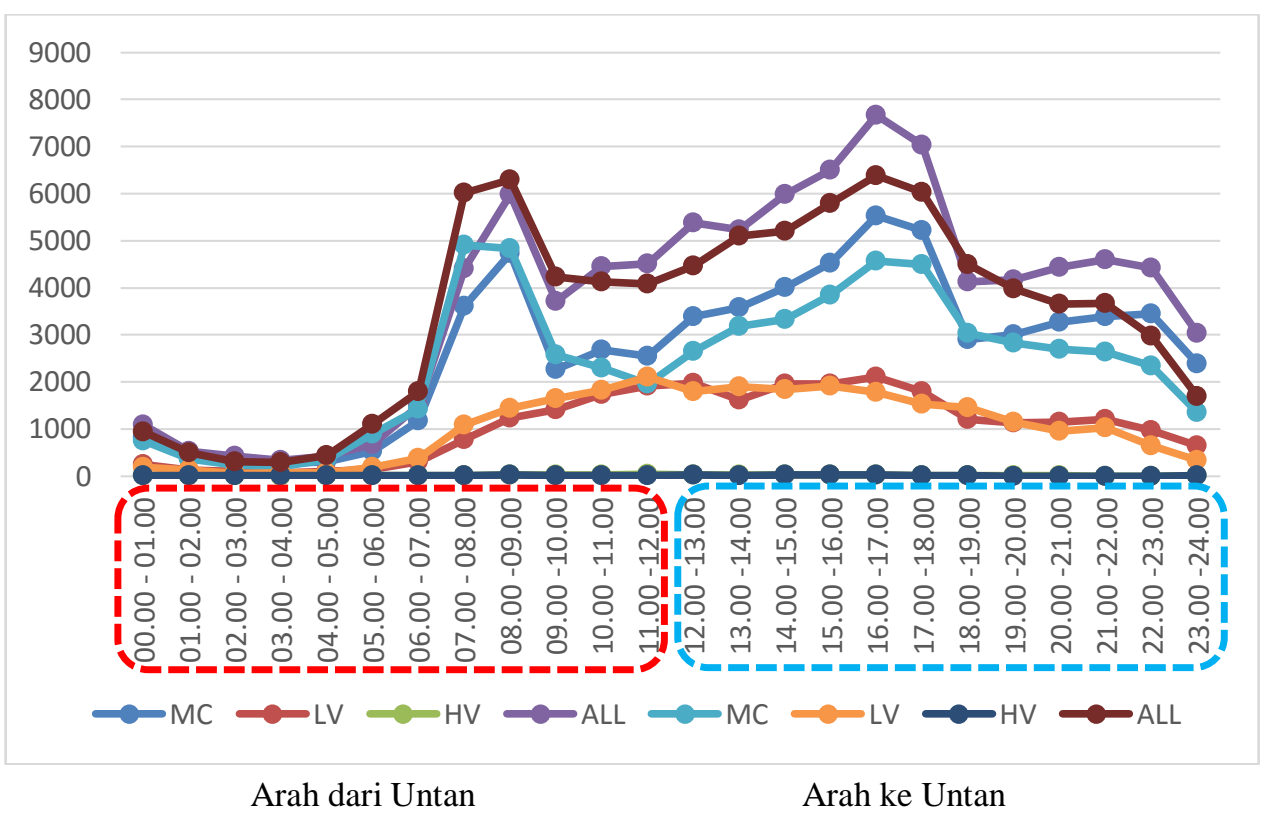

Gambar 5. Volume kendaraan di Jalan Ahmad Yani hari Senin

Fluktuasi volume pada hari Minggu sebagai representasi kondisi lalu-lintas di akhir pekan sebagaimana pada gambar berikut:

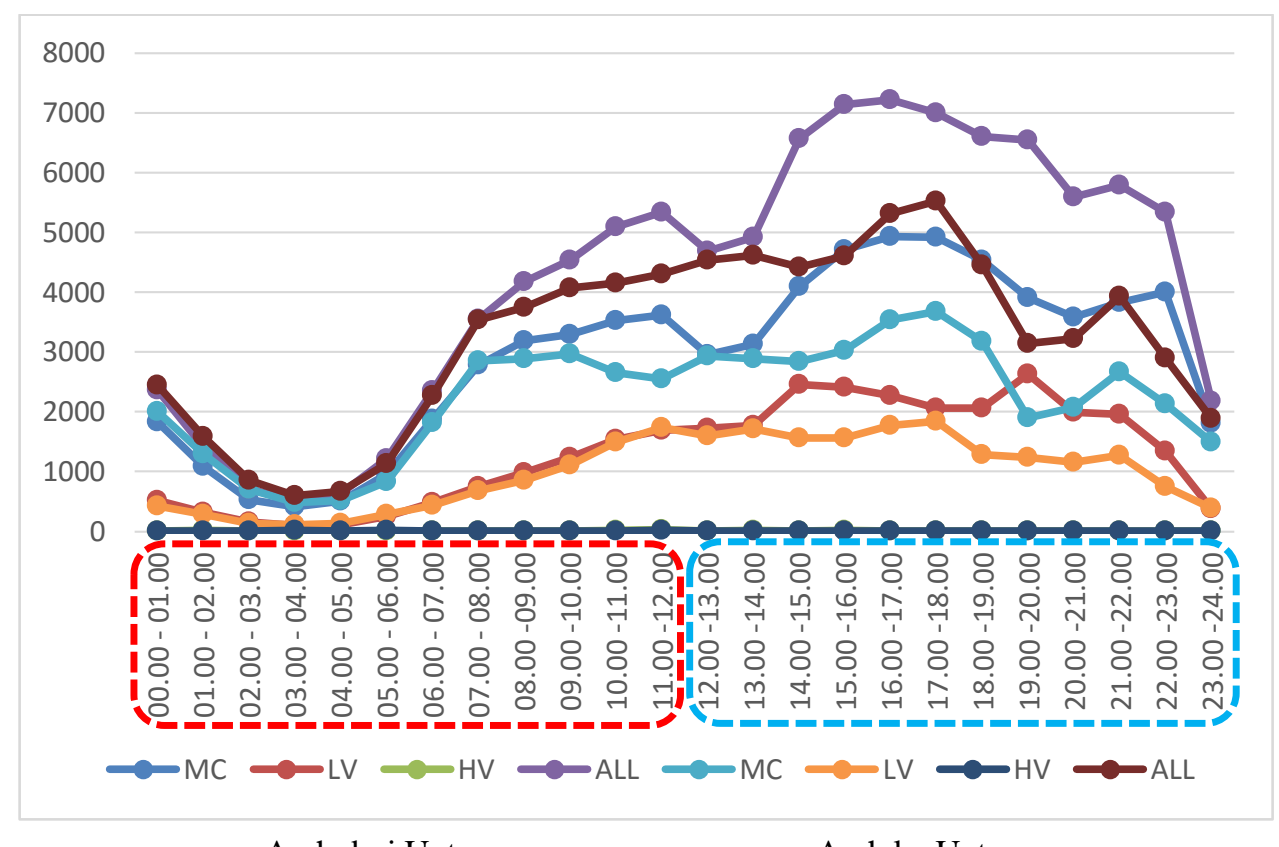

Arah dari Untan

Arah ke Untan

Gambar 6. Volume Kendaraan di Jalan Ahmad Yani hari Minggu

\section{Perilaku dan Persepsi Berkendara}

Perilaku pengendara baik pengendara kendaraan ringan maupun khususnya sepeda motor didapatkan dari rekaman CCTV, sedangkan survei secara online dilakukan untuk dapat memahami persepsi pengendara di jalan raya. Pengolahan data yang dilakukan dari hasil penelitian yang pernah dilakukan sebelumnya oleh Pratama (2014) bahwa 55,3\% sepeda 
motor keluar dari lajur khusus sepeda motor yang telah disediakan, untuk jenis kendaraan ringan sangat kecil sekitar $0,73 \%$ yang memasuki lajur khusus sepeda motor. Serupa dengan hasil penelitian tersebut, dari penelitian ini bahwa sekitar $44 \%$ kendaraan jenis MC menggunakan lajur yang diperuntukkan roda 4 atau lebih, sementara jenis LV berkisar 8$11 \%$.

Persepsi pengemudi dalam pengendara didapatkan dari survei yang dilakukan secara online. Dari 300 responden yang diharapkan, terjaring 100 orang. Jumlah responden sebanyak 100 sudah cukup untuk mendeskripsikan responden, karena sampel sebanyak 30 sudah tergolong sampel besar, selain itu juga tergantung sebaran/homogenitas yang dinyatakan dengan nilai $\mathrm{CoV}$ (coefficient of variation). Penelitian ini menggunakan dua konsep psikologi yaitu Risk taking culture, meliputi belief, sikap intensi, dan norma subyektif (Eiksund, 2009); dan risk perception, yaitu persepsi terhadap risiko kemungkinan terjadinya kecelakaan lalu lintas Cohn, dkk (1995, dalam Machin \& Sankey, 2007). Pertanyaan sebanyak 68 butir digolongkan menjadi beberapa bagian. Pertama adalah bagaimana kemungkinan terjadinya kecelakaan walau responden sudah memiliki kecakapan mengemudi. Kedua adalah tentang perilaku ngebut (speeding) di jalan raya. Ketiga, tentang pemberlakuan pembatasan kecepatan di jalan raya. Keempat, sangksi atau hukuman bagi pelanggar lalu-lintas. Kelima, kecepatan dalam berkendara di beberapa jenis/fasilitas jalan seperti di jalan bebas hambatan, jalan luar kota, dan dalam kota. Keenam, tentang pendapat responden berkaitan dengan kepatuhan ketika berkendara.

\section{PEMBAHASAN}

\section{Marka dan Rambu}

Di jalan Ahmad Yani, marka dan rambu telah tersedia dengan jumlah yang memadai dan dalam keadaan baik seperti jelas terlihat, posisi atau penempatan sesuai sehingga mudah diikuti untuk patuh dalam berkendara.

\section{Kecepatan Kendaraan}

Pada hari kerja (workday), kecepatan kendaraan di pagi hari (lalu-lintas ramai) lebih tinggi dibandingkan menjelang siang (lalu-lintas lengang) untuk semua jenis kendaraan. Hal ini berbeda ketika malam hari. Kecenderungan ini nampak jelas di jalan Ahmad Yani di depan Gedung Kejaksaan Kalimantan Barat. Sementara, untuk kondisi di jalan Ahmad Yani depan Ayani Mega Mal agak sulit menarik kesimpulan karena sangat variatif.

\section{Volume Kendaraan}

Jalan Ahmad Yani mempunyai volume lalu-lintas yang besar melebihi 100 ribu kendaraan perhari untuk 2 arah yang diamati dari tahun 2014 dan 2019, dimana mempunyai kecenderungan bertambah di setiap tahun. Proporsi sepeda motor sekitar 70\%, kendaraan ringan 29,6\% dan kendaraan berat 0,4\%. Pada pengamatan di bulan Mei 2019 bahwa jam sibuk pagi dan sore dipengaruhi oleh jumlah sepeda motor, sementara untuk jenis kendaraan ringan (LV) jam puncak terjadi di siang hari dari pukul 11.00 s.d. 13.00 dan sore hari pukul 16.00 s.d. 18.00. Kecenderungan ini untuk kedua arah di jalan tersebut khususnya pada hari kerja (workday), sedangkan pada hari Minggu atau (weekend) bahwa jam puncak terjadi di siang hari pada pukul 10.00 s.d 12.00 untuk jenis sepeda motor 
maupun kendaraan ringan, juga jam puncak sore hari sekitar pukul 16.00 s.d.18.00 pada hari kerja (workday).

\section{Perilaku Berkendara}

Disiplin berlalu lintas khususnya pengendara sepeda motor berkaitan dengan disiplin berkendara di lajur sepeda motor relatif kecil. Berdasarkan elaborasi data hasil penelitian Pratama (2014) bahwa sekitar 55\% kendaraan sepeda motor tidak berada di jalur sepeda motor yang disediakan. Sejalan dengan hasil tersebut, pangamatan yang dilakukan pada penelitian ini bahwa sekitar $44 \%$ kendaraan jenis sepeda motor tidak menggunakan lajur yang telah disediakan khusus sepeda motor.

\section{Persepsi Berkendara}

Persepsi pengendara terhadap kemungkinan terjadi kecelakaan walau mempunyai ketrampilan mengemudi dan pengalaman berkendara sekitar $61 \%$ hingga $80 \%$. Pengendara ngebut di jalan mempunya alasan (lebih dari 50\%) karena cepat sampai, supaya tepat waktu, sedangkan mereka tidak setuju ngebut di jalan dengan alasan untuk uji nyali, menghilangkan stress, menyalurkan hoby, mengurangi rasa kantuk, agar lebih berkonsenterasi, menunjukkan ketrampilan mengemudi, mendapa pujian, menghindari razia, menyalurkan emosi, agar lebih percaya diri, bangga bisa mendahului kendaraan didepannya, didorong teman atau pengendara lain, dikatakan pengecut. Persepsi pengendara terhadap pembatasan kecepatan kendaraan di jalan raya beranggapan dapat mengurangi jumlah kecelakaan dan mengurangi fatalitas dan bisa mengendalikan kendaraan, sedangkan hanya sedikit (13\%) yang menyatakan supaya lebih waspada dalam berkendara dan hanya 6\% yang patuh terhadap rambu tersebut. Sanksi denda uang yang besar disetujui ketika pengendara melanggar batas kecepataan. Demikian pula pencabutan SIM untuk sementara, namun tidak untuk pencabutan SIM secara permanen. Pengendara memacu kecepatan kendaraan di jalan bebas hambatan lebih tinggi dibanding saat berada di jalan satu arah, dan kecepatan lebih rendah lagi ketika berada di jalan 2 jalur 2 arah seperti umumnya pada jalan konvensional di luar kota (rural road). Menariknya walau tidak untuk ditiru bahwa kebiasaan menelpon saat berkendara masih sangat besar yakni sekitar $58 \%$ responden yang menyatakan pernah melakukan.

\section{KESIMPULAN}

Terdapat beberapa hal yang menarik dalam kajian ini bahwa jalan Ahmad Yani yang bersatus Jalan Nasional mempunyai fungsi yang sangat penting dimana terlihat jumlah volume lalu-lintas hampir 200 ribu kendaraan. Jam puncak saat hari kerja terjadi pukul 6.00 s.d. 8.00 dimana didominasi jenis sepeda motor, sedangkan jenis kendaraan ringan jam puncak terjadi pukul 10.00 s.d. 12.00. Pada hari Minggu jam puncak terjadi sekitar pukul 16.00 s.d. 17.00 untuk kedua arah.

Pengendara sepeda motor tidak disiplin menggunakan lajur khusus sepeda motor yang telah disediakan mencapai sekitar $44 \%$ dan $55 \%$ berdasarkan 2 tahun pengamatan.

Kecepatan kendaraan di pagi hari lebih besar saat lalu-lintas padat dibandingkan ketika jam-jam lengang. Keadaan ini berbanding terbalik ketika malam hari.

Perilaku ngebut di jalan disebabkan faktor ingin cepat sampai di tempat tujuan atau datang lebih awal. 


\section{UCAPAN TERIMAKASIH}

Terimakasih yang besar kami sampaikan kepada Korlantas Polri yang telah membiayai penelitian pada Batch 4 ini melalui Hibah Traffic Accident Research Center (TARC), dan dukungan Direktorat Lalu Lintas Kepolisian Daerah Kalimantan Barat. Juga semua kolega Forum Studi Transportasi antar Perguruan Tinggi (FSTPT) yang memfaslitasi kegiatan Hibah TARC tahun 2019.

\section{DAFTAR PUSTAKA}

Cohn, L.D., Macfarlane, S., Yanez, C., Imai, W.K., (1995), "Risk-perception:differences between adolescents and adults", Health Psychol. 14 (3), 217-222.

Dinas Perhubungan Kalbar (2017), "Penyusunan Studi Daerah Kecelakaan di Ruas Jalan Ng.Tayap-Manis Mata, Ketapang-Kendawangan, Sp.Pelang-Batu Tajam, Tlk Batang-Sp.Siduk", unpublished

Ditjen Bina Marga (1997), "Manual Kapasitas Jalan Indonesia", SWEROAD \& PT.(Persero) Bina Marga.

Ditjen Bina Marga (2013), "Standar Biaya Penanganan Jalan Tahun 2011 dan 2012", Kementerian PU, Jakrta.

Eiksund, S. (2009), "A geographical perspective on driving attitudes and behaviors among young adults in urban and rural Norway", Safety Science, 47(4), 529-536.

Finch, D.J., Kompfner, P., Lockwood, C.R., Maycock, G., (1994), "Speed, speed limits and accidents", TRL project report 58, Transport Research Laboratory, Crowthorne, UK.

https://mediaindonesia.com/read/detail/132294-indonesia-juara-2-tingkat-kecelakaan-seasean

https://nasional.sindonews.com/read/947769/163/10-pelanggaran-lalu-lintas-paling-sering-terjadi$\underline{1420695422}$

Ismurdianto (2013), "Rencana Alternatif Geometrik Persimoangan Jalan Ahmad Yani", Skripsi Universitas Tanjungpura, Pontianak.

Machin, M.A., Sankey, K.S., (2008), "Relationship between young driver's personality characteritics, risk perceptions, and driving behaviour", Elsvier.

Pratama, E. P., (2014), "Kajian Lajur Khusus Sepeda Motor Pada Jalan Ahmad Yani Pontianak", Skripsi, Universitas Tanjungpura, Pontianak.

Zainuddin (2016), "Disain Rencana Underpass Sebagai Jalur Alternatif Pengendara Sepeda Motor dan Prasarana Penyeberangan Pejalan Kaki”, Skripsi, Universitas Tanjungpura, Pontianak. 